\title{
Respon Pertumbuhan Tanaman Lidah Mertua (Sansivera Sp) Yang dibudidaya Pada Jenis Media Tanam Tanah Berbeda Dengan Pemberian Pupuk Bokashi Hijauan Daun Kudo
}

\author{
${ }^{1}$ Iinnaninengseh, ${ }^{2}$ Jasni Ayuswastika \\ Program Studi Agroteknologi Fakultas Ilmu Pertanian Universitas Al Asyariah Mandar \\ ${ }^{1}$ iinnaninengseh74@yahoo.com \\ ${ }^{2}$ jasni.j@yahoo.com
}

\begin{abstract}
Abstrak
Lidah mertua adalah salah satu komoditas hortikultura yang tahan terhadap kekeringan yang mampu menyerap lebih dari 107 unsur polutan yang ada dan berbahaya di udara.Tempat tumbuh Keasaman $(\mathrm{pH})$ media tanam yang ideal untuk Sansevieria adalah 5,5-7,5. Meskipun demikian tanaman ini bisa bertoleransi pada rentang pH 4,5-8,5. Pada kondisi asam, penyerapan hara nitrat dan fosfor akan terhambat. Penelitian ini bertujuan untuk mengetahui respon pertumbuhan tanaman lidah mertua (sansivera $s p$.) yang dibudidaya pada jenis media tanam tanah berbeda dengan pemberian pupuk bokashi hijauan daun kudo. berlangsung dari bulan september sampai desember 2016.Dalam penelitian ini menggunakan rancangan acak kelompok pola faktorial terdiri dari dua faktor yaitu.Faktor pertama yang terdiri dari dua taraf yaitu: Jenis media tanam tanah berbeda (T) yang terdiri dari dua taraf yaitu media tanah lahan tegalan (T1) dan media tanah salin(T2).Faktor kedua adalah pemberian pupuk bokashi hijauan daun kudo yang terdiri dari tiga taraf yaitu: tanpa pemberian pupuk (B0),pemberian pupuk 100g/polybag (B1) dan pemberian pupuk 200g/polybang (B2). Hasil penelitian menunjukkan bahwa interaksi antara jenis media tanam tanah berbeda dengan pemberian pupuk bokashi hijauan daun kudo $(\mathrm{TxB})$ tidak memberikan pengaruh terhadap parameter pengamatan. Namun tanpa pemberian pupuk bokashi hijauan daun kudo (B0) memberikan pengaruh baik terhadap parameter tinggi tanaman dan jenis media tanam tanah yang berbeda (T) tidak memberikan pengaruh baik terhadap parameter yang diukur.
\end{abstract}

Kata Kunci : Lidah Mertua, Media Tanam, Pupuk Bokashi

\section{PENDAHULUAN}

Lidah Mertua adalah tanaman hias yang berasal dari benua Afrika ini bermanfaat sekali bagi udara lingkungan. Lidah Mertua atau dalam bahasa ilmiah disebut Sansivera berguna bagi manusia karena lidah mertua mampu menyerap lebih dari 107 unsur polutan yang ada dan berbahaya di udara. Kemampuan menyerap Zat Polutan itu, karena Sansivera memiliki bahan aktif Pregnane Glikosid, yang berfungsi untuk mereduksi polutan menjadi Asam Organik, Gula dan Asam Amino (Juli Saniati 2014).

Lidah Mertua dibagi menjadi dua jenis, yaitu yang tumbuh memanjang ke atas dengan ukuran 50$75 \mathrm{~cm}$ dan yang berdaun pendek melingkar dalam bentuk roset dengan panjang $20 \mathrm{~cm}$ dan lebar 3-6 $\mathrm{cm}$. Kelompok panjang memiliki daun meruncing seperti mata pedang dan oleh sebab itu Sansivera disebut sebagai tanaman pedang-pedangan. (Anggraini 2010).

Agrovital | Jurnal Ilmu Pertanian Universitas Al Asyariah
Lidah Mertua mulai dibudiayakan saat ini karena keindahan struktur dan warna daunnya. Biasanya tanaman ini diletakkan di dalam ruangan seperti kantor ataupun hotel. Dengan bentuk, warna, ukuran, dan corak daun yang bervariasi menyebabkan tanaman ini bernilai ekonomi tinggi, mampu menyerap racun di udara dan bisa juga di jadikan obat (Anggraini 2010).

Tanah merupakan campuran bahan padat (organik dan anorganik), dan udara ketiga fase ini saling mempengaruhi satu sama lain. Misalnya reaksi-reaksi bahan padat berpengaruh terhadap kualitas udara air, berpengaruh terhadap pelapukan bahan jasad renik dan sebagainya. (Rina 2012).

Tanah salin adalah tanah yang mengandung garam mudah larut yang jumlahnya cukup besar bagi pertumbuhan kebanyakan tanaman seperti $\mathrm{NaCl}$. Pada lahan-lahan pantai sering memunculkan tanahtanah salin sebagai akumulasi garam akibat kekeringan musim kemarau. Bahan organik didalam 
tanah dapat berperan sumber unsur hara, memelihara kelembaban tanah, sebagai penghemat unsur-unsur penyebab salinitasi sehingga dapat meningkatkan ketersediaan unsur-unsur hara kandungan bahan organik kurang dari 1\% menyebabakan tanah tidak mampu menyediakan unsur hara yang cukup.

Pupuk adalah unsur hara yang diberikan kepada tanah maupun tanaman, pemberian pupuk terhadap tanaman sangat penting untuk pertumbuhanya, karena tanaman memerlukan banyak sekali hara untuk memperbaiki pertumbuhannya. Sehingga dilalukan pemupukan agar unsur hara yang dibutuhkan tanaman cukup terpenuhi. Pupuk yang digunakan untuk memupuk tanaman pelindung dan tanaman hias untuk memperindah kota pupuk organik yang hasil dari sisa bahan organik, dedaunan yang gugur dan sisa-sisa pembakaran bisa di jadikan pupuk organik. Salah satu pupuk yang bersumber dari dedaunan tanaman yaitu bokashi hijauan daun kudo yang dimana pupuk ini bersumber dari bahanbahan alami mengandung unsur hara, yang akan mampu memperbaiki struktur tanah yang padat menjadi gembur dan memperbaiki sifat fisik kimia, dan biologi tanah. Pupuk bokashi hijauan daun kudo mengandung unsur hara makro dan mikro, pupuk bokashi hijauan daun kudo sangatlah penting bagi pertumbuhan dan perkembangan tanaman, dimana tanaman memerlukan banyak sekali unsur hara untuk pertumbuhannya.

Pupuk bokashi hijauan daun kudo adalah salah satu pupuk organic yang dapat memperbaiki struktur tanah yang sebagian besar yang telah menjadi keras akibat penggunaan pupuk kimia terus-menerus, jika diberikan pada tanaman lidah mertua diharapkan akan memperbaiki dan meningkatkan hasil produksi. Penelitian ini guna untuk mengembagkan tanaman hias seperti lidah mertua (sansiviera $s p$ ).

\section{METODE PENELITIAN}

\section{a. Tempat Dan Waktu}

Penelitian ini akan direncanakan Di Desa Mekkatta Kecamatan Malunda Kabupaten Majene, pada bulan September sampai bulan Desember 2016.

\section{b. Metode Pelaksanaan}

Penelitian ini akan dilaksanakan dengan menggunakan Rancangan Acak Kelompok (RAK) dengan model faktorial terdiri dari dua faktor yaitu:

Faktor pertama jenis media tanam tanah berbeda (T), yang terdiri dari dua taraf perlakuan yaitu: (T1 ) Media tanam tanah lahan tegalan, (T2 )
Media tanam tanah salin. Adapun faktor kedua takaran pupuk bokashi hijauan daun kudo (B) terdiri dari tiga taraf yaitu : ( B0 )Tanpa pemberian pupuk bokashi hijauan kudo, ( B1 ) 100 gr/polybag pemberian pupuk bokashi hijauan kudo, ( B2 ) 200 gr/polybag pemberian pupuk bokashi hijauan kudo.

Dimana setiap kombinasi perlakuan diulang sebanyak tiga kali dan terdapat 18 unit penelitian, dalam setiap unit terdapat dua tanaman, sehingga jumlah tanaman seluruhnya 36 tanaman. Tinggi tanaman (cm); di ukur dari pangkal batang sampai titik tumbuh terakhir, dilakukan sekali dalam dua minggu, Lingkaran batang ( $\mathrm{cm})$; diukur lingkaran satu tanaman, dilakukan sekali dalam dua minggu. Jumlah daun (helai); di hitung sejak munculnya daun, dihitung sekali dalam dua minggu.

\section{HASIL DAN PEMBAHASAN \\ Tinggi Tanaman}

Berdasarkan Sidik ragam menunjukkan bahwa jenis media tanam tanah berbeda (T) tidak memberikan pengaruh nyata namun tanpa pupuk bokashi hijauan daun kudo (B) pengaruhnya sangat nyata sedangkan interaksinya jenis tanam tanah dengan takaran pupuk bokashi hijauan daun kudo $(\mathrm{TxB})$ juga pengaruhnya tidak nyata terhadap tinggi tanaman Lidah mertua.

Tabel 1. Rata-rata Tinggi Tanaman (cm) Pada Respon Pertumbuhan Tanaman Lidah Mertua (Sansivera sp.) yang dibudidaya Pada Jenis Media Tanam Tanah Berbeda Dengan Pemberian Pupuk Bokashi Hijauan Daun Kudo.

\begin{tabular}{|c|c|c|c|c|}
\hline \multirow{2}{*}{$\begin{array}{c}\text { Media } \\
\text { Tanam } \\
\text { Tanah } \\
(\mathrm{T})\end{array}$} & \multicolumn{3}{|c|}{ Pupuk Hijau Kudo (B) } & \multirow{2}{*}{$\begin{array}{l}\text { Rata-rata } \\
\text { NP-UJBD }\end{array}$} \\
\hline & B0 & B1 & B2 & \\
\hline $\mathrm{T} 1$ & $\underset{\mathrm{a}}{16,71}$ & $\underset{\mathrm{a}}{13,00}$ & $\underset{\mathrm{a}}{13,70}$ & 14,47 \\
\hline $\mathrm{T} 2$ & $\begin{array}{l}15,67 \\
a b\end{array}$ & $\underset{\mathrm{b}}{13,53}$ & $\underset{\mathrm{b}}{10,35}$ & 13,35 \\
\hline $\begin{array}{c}\text { Rata- } \\
\text { rata }\end{array}$ & 16,19 & 13,26 & 12,03 & \\
\hline $\begin{array}{c}\text { Np- } \\
\text { UJBD } \\
\text { Taraf } \alpha \text {, } \\
0.01\end{array}$ & 4,56 & 4,82 & & \\
\hline
\end{tabular}

Keterangan : Angka-Angka Yang Diikuti Oleh Huruf Yang Tidk Sama Berarti Berbeda Nyata Pada UJBD Taraf, $\alpha, 0,01$. 
Hasil penelitian menunjukkan bahwa tanpa pemberian pupuk hijauan daun kudo pengaruhnya lebih baik pada parameter tinggi tanaman. Hal ini menunjukkan bahwa pupuk hijauan kudo yang diaplikasikan pada media tanam tanah berbeda untuk budidaya lidah mertua belum sepenuhnya terurai sehingga unsur yang terkandung dan pupuk hijauan daun kudo belum dapat diserap oleh tanaman lidah mertua. Namun tanaman tetap melakukan proses pertumbuhan dalam rangka pertambahan ukuran atau volume fisik tanaman agar tanaman lidah mertua tetap dapat melaksanakan aktifitas pertumbuhan fotosintesis dalam hal ini organ-organ tanaman. pada tanaman lidah mertua tetap aktif melakukan aktifitas fotosintesis dalam hal ini mensuplai azimilat kesuburan organ tanaman. Dosis pupuk bokashi hijauan daun kudo yang digunakan diduga dosisnya masih terlalurendah dan pengaplikasian pupuk tidak sesuai batas waktu yang ditentukan atau tidak sesuai dengan kebutuhan nutrisi yang diperlukan oleh tanaman lidah mertua.

Hal ini diperkuat oleh Soegiman (1982) bahwa suatu tanaman akan tumbuh dan mencapai tingkat produksi tinggi apabila unsur hara yang dibutuhkan tanaman berada dalam keadaan cukup tersedia dan berimbang di dalam tanah dan unsur $\mathrm{N}, \mathrm{P}, \mathrm{K}$ merupakan tiga unsur dari enam unsur hara makro yang mutlak diperlukan oleh tanaman. Bila salah satu unsur tersebut kurang atau tidak tersedia dalam tanah,akan mempengaruhi pertumbuhan dan produksi tanaman. Lebih lanjut lagi diutarakan oleh Sutedjo (1992). Bahwa pertumbuhan dan perkembangan suatu jenis tanaman selain ditentukan oleh ketersediaan unsur hara yang tersedia.

\section{Lingkaran Batang}

Hasil pengamatan lingkaran batang dan sidik ragamnya disajikan pada Tabel Lampiran $2 \mathrm{a}$ dan $2 \mathrm{~b}$. Sidik ragam menunjukkan bahwa jenis media tanam tanah berbeda $(\mathrm{T})$ tidak memberikan pengaruh nyata demikian pula dengan takaran pupuk bokashi hijauan daun kudo (B) dan interaksi jenis tanam tanah berbeda dengan takaran pupuk bokashi hijauan daun kudo (TxB) juga tidak berpengaruh nyata terhadap lingkar batang tanaman lidah mertu.

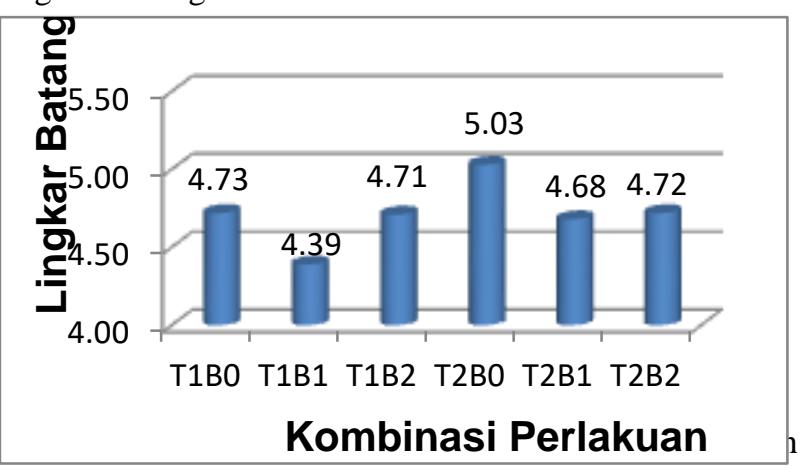

Gambar 1. Diagram Batang Lingkaran Batang (Cm) Pada Respon Pertumbuhan Tanaman Lidah Mertua (Sansivera Sp) Yang Dibudidaya Pada Media Tanam Tanah Berbeda Dengan Pemberian Pupuk Bokashi Hijauan Daun Kudo.

Berdasarkan fakta penelitian baik jenis media tanam pada lingkar batang tanaman lidah mertua yang dibudidaya pada jenis media tanam tanah $(\mathrm{T})$ yang berbeda dengan pemberian pupuk bokashi hijauan daun kudo (B) tidak memberikan pengaruh baik. Bahwa jenis media tanam tanah lahan kering dan jenis tanah salin yang dikombinasikan dengan berbagai dosis pupuk bokashi hijauan daun kudo belum terserap oleh tanaman lidah mertua hal ini diduga karena bokashi hijauan kudo belum terurai dengan sempurna, sehingga unsur-unsur yang dikandungnya tersedia atau memenuhi kebutuhan nutrisi bagi tanaman lidah mertua di media tanah tegal maupun media tanah salin. Karena tinggi tanaman merupakan salah satu indikator pertumbuhan. Sehingga diikuti juga oleh parameter yang lain, takaran pupuk bokashi hijauan daun kudo tidak sesuai dan maksimal dikarenakan penguraiannya lambat.

Menurut Harjadi (1991), ketersediaan unsur hara bagi tanaman merupakan salah satu faktor penting untuk menunjang pertumbuhan dan perkembangan tanaman karena unsur hara ini mempunyai peranan penting sebagai sumber energi dan penyusunan stuktural tanaman. Tanpa tambahan suplai unsur hara yang cukup unsur hara dapat menyebabkan pertumbuhan terganggu.

\section{Jumlah Daun}

Hasil pengamataan jumlah daun dan sidik ragamnya disajikan pada tabel lampiran $3 a$ dan $3 b$, sidik ragam menunjukkan bahwa jenis media tanam tanah (T) tidak memperlihatkan pengaruh nyata begitupun takaran pupuk bokashi hijauan daun kudo (B) juga tidak berpengaruh sehingga interaksi jenis tanam tanah berbeda dengan takaran pupuk bokashi hijauan daun kudo (TxB) tidak menunjukkan pengaruh nyata terhadap jumlah daun tanaman lidah mertua.

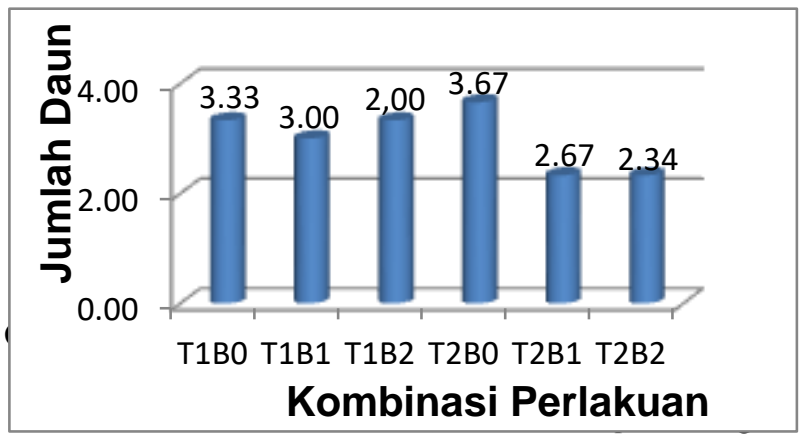


Dibudidaya Pada Jenis Media Tanam Tanah Berbeda Dengan Pemberian Pupuk Bokashi Hijauan Kudo.

Daun adalah suatu organ yang menjadi pensuplai makan azimilat terbesar pada tanaman. hasil jumlah daun pada tanaman lidah mertua yang dibudidaya pada jenis media tanam tanah tegal (T1) dan media tanah salin (T2) yang dinteraksikan dengan pemberian pupuk bokashi hijauan daun kudo (B) tidak memberikan respon yang baik. Hal ini dimunkinkan karena daun sebagai pensuplai azimilat tidak memperbaiki suplai azimilat fotosintesis yang sesuai dengan kebutuhan nutrisi yang diperlukan oleh tanaman sansivera, dikarenakan dosis pupuk daun kudo yang diberikan kepada tanaman sansivera tidak mencukupi kebutuhan hara yang diperlukan, kemudian pula dengan media tanah tegalan dengan tanah salin penguraianya lambat dan yang digunakan adalah tanah yang belum pernah diolah atau ditanami tanaman sebelumnya baik pemupukan atau output yang lainya

Ketika suplai hara di akar ketubuh tanaman lidah mertua optimal maka daun sebagai media fotosintesis juga tidak akan optimal karena bokahi hijauan daun kudo belum terurai hingga belum dapat absorsi tanaman dalam hal ini jumlah daun pertumbuhannya tidak optimal.

\section{KESIMPULAN}

Berdasarkan hasil penelitian yang dilakukan maka dapat di tarik kesimpulan bahwa:

1. Interaksi antara jenis media tanam tanah dengan takaran pemberian pupuk bokashi hijauan daun kudo (TxB) tidak memberikan pengaruh baik terhadap parameter yang diukur.

2. Tanpa pemberian pupuk bokashi hijauan daun kudo (B0) memberikan pengaruh baik terhadap parameter tinggi tanaman

3. Jenis media tanam tanah berbeda (T) tidak memberikan pengaruh baik terhadap parameter yang diukur.

\section{DAFTAR PUSTAKA}

Angraini (2010). Pengaruh Media Dan Sumber Bahan Tanaman Terhadap Pertumbuhan Stek Lidah Mertua [Skripsi] Medan: Universitas Sumatra Utara.

Aphani 2001. Media Tanah Salin. (Https://Id.Scribd.Com).

Anonim 2008. Syarat Tumbuh Sansivera. (http//www. Dunia Flora). Universitas Sumatera Utara.
Anonim,2008.(http://azaganteng.blogspot.com/fotosi ntesis.html). Diakses pada tanggal 20 maret 2014

Addien, 2009.Menanam Dan Merawat Tanaman Hias. Bandung. Pt Sarana Ilmu Pustaka.

Ashari, 2016. Media Tumbuh Tanaman. (www.Google).

Azzamy, 2015. Pengertian Bokashi. (Http://,Mitalon.Com).

Cahyo, 2016. Pupuk Hijau Dan Cara Membuatnya. (Http://,Artikel.Co.id).

Danial , M., N. A. S. Taufeiq, dan W. Sanusi. 2011. Pemanfaatan Zeolit Dan Bokashi Ampas Tahu Untuk Menekan Konsentrasi Nikel Dan Menigkatkan Tanaman Jagung.berk.panel.

Darmawan dan J. Baharsyah. 1983 Dasar Dasar Fisiologi Tanaman. Suryandara Utama,Semarang

Fredikurniawan, 2013. Klasifikasi Dan Morfologi Tanaman Sansivera. (Http://,www.Tanamanku.Net).

Gardener, dkk , 1991 . Fisiologi Tanaman Budidaya, Penerbit Universitas Indonesia, Jakarta.

Hardjadi, 2002. Pengantar Agronomi. PT Gramedia, Jakarta

Juli Saniati, 2014, Makalah Kota Indah Dan Sehat Dari Polusi Udara Dengan Lidah Mertua. (https//.julisaniati.wordpres.com).universitas negeri padang.

Nurmadinah, 2015, Uji penggunaan pupuk bokashi daun srikaya dengan penyungkupan tempurung terhadap pertumbuhan tanaman kencur hal 7 . Universitas Al_Asyariah Mandar

Poewewidodo, 1992. Telah Kesuburan Tanah. Penerbit Angkasa.

Santoso, 2006. Syarat Tumbuh Tanaman Sansivera. (Dunia Flora.Com).

Sarief. S, (1989), Kesuburan dan Pemupukan Tanah Pertanian. Pustaka Buana, Bandung.

Setyamidjaja. D, 1986. Pupuk dan Pemupukan. CV Simplex, Jakarta.

Setyati. S, 1988. Pengantar Agronomi. PT. Gramedia, Jakarta.

Soegiman, 1982. Ilmu Tanah (telah diterjemahkan) Bhratara Karya Aksara, Jakarta.

Sutedjo, M.M, 1992. Analisa Tanah, Air dan Jaringan Tanaman. PT Rineka Cipta Jakarta.

Sutedjo M.M, 2002. Pemupukan dan cara pemupukan. PT Rineka Cipta, Jakarta.

Sutiyono, 2010.Pengaruh Media Tanam Terhadap PertumbuhanTanaman.(Http://www.Tanaman ku.Com).

Syaifuddin, 1998. Udara Bersih Sebagai Kebutuhan Hidup.Bandung. 
Syafullah, 2011.Seputar Budidaya Tanaman Hias. Singkawan Kalimantan Barat. Pt Marga Borneo Tarigas.
Yossi Heflindah, 2015. Pembuatan Pupuk Bokashi Serta Manfaat Dan Kegunaanya. (Blogspot.Com). 